Word Count: 199 (abstract) 2649 (body)

Figures: 2 Tables: 3

Supplementary material: none

\title{
Impaired response inhibition and excess cortical thickness as candidate
} endophenotypes for trichotillomania

\author{
Samuel R Chamberlain, M.D. Ph.D. ${ }^{1 *}$ Brian L. Odlaug, M.P.H. ${ }^{2^{*}}$ \\ Katie L. Derbyshire, B.S. ${ }^{3}$ Eric W. Leppink, B.A. ${ }^{3}$ \\ Jon E. Grant, J.D., M.D., M.P.H. ${ }^{3 * *}$
}

${ }^{1}$ Department of Psychiatry, University of Cambridge, UK; \& Cambridge and Peterborough NHS Foundation Trust (CPFT), UK

${ }^{2}$ Department of Public Health, Faculty of Health and Medical Sciences, University of Copenhagen, Copenhagen, Denmark

${ }^{3}$ Department of Psychiatry \& Behavioral Neuroscience, University of Chicago, Chicago, IL USA

*Co-first authors **Address correspondence to:

Jon E. Grant, JD, MD, MPH

Department of Psychiatry \& Behavioral Neuroscience, University of Chicago, Pritzker

School of Medicine, 5841 S. Maryland Avenue, MC 3077; Chicago, IL 60637

Phone: 773-834-1325; Fax: 773-834-6761; Email: jongrant@uchicago.edu

Key Words: cognition; compulsivity; imaging; impulsivity; trichotillomania;

endophenotype

Short title: Cortical thickness in trichotillomania 


\begin{abstract}
Trichotillomania is characterized by repetitive pulling out of one's own hair. Impaired response inhibition has been identified in patients with trichotillomania, along with grey matter density changes in distributed neural regions including frontal cortex. The objective of this study was to evaluate impaired response inhibition and abnormal cortical morphology as candidate endophenotypes for the disorder. Subjects with trichotillomania $(\mathrm{N}=12)$, unaffected first-degree relatives of these patients $(\mathrm{N}=10)$, and healthy controls $(\mathrm{N}=14)$, completed the Stop Signal Task (SST), a measure of response inhibition, and structural magnetic resonance imaging scans. Group differences in SST performance and cortical thickness were explored using permutation testing. Groups differed significantly in response inhibition, with patients demonstrating impaired performance versus controls, and relatives occupying an intermediate position. Permutation cluster analysis revealed significant excesses of cortical thickness in patients and their relatives compared to controls, in right inferior/middle frontal gyri (Brodmann Area, BA 47 \& 11), right lingual gyrus (BA 18), left superior temporal cortex (BA 21), and left precuneus (BA 7). No significant differences emerged between groups for striatum or cerebellar volumes. Impaired response inhibition and an excess of cortical thickness in neural regions germane to inhibitory control, and action monitoring, represent vulnerability markers for trichotillomania. Future work should explore genetic and environmental associations with these biological markers
\end{abstract}




\section{Introduction}

Trichotillomania (also known as Hair Pulling Disorder) is an often debilitating psychiatric condition characterized by recurrent pulling out of one's own hair, leading to hair loss and marked functional impairment (Odlaug et al., 2010; Woods et al., 2006). While the phenomenon of hair pulling has been described since antiquity (such as in work attributed to Hippocrates), trichotillomania was first recognized as a distinct clinical entity by the French dermatologist Francois Hallopeau in the $19^{\text {th }}$ Century (Hallopeau 1889). Subsequently, trichotillomania was incorporated into psychiatric nosology, first as an Impulse Control Disorder in the Diagnostic and Statistical Manual $3^{\text {rd }}$ Edition (DSMIII-R), and then as an Obsessive Compulsive Related Disorder in the $5^{\text {th }}$ Edition (DSM-5). The clinical and research importance of trichotillomania is increasingly recognized. Far from being rare, trichotillomania is relatively common, with point prevalence estimates of $0.5-4 \%$ (Odlaug and Grant, 2010) and lifetime prevalence estimates of around $0.6 \%$ (Christenson et al., 1991). Animal models of excessive grooming have been widely touted as being valuable not only in understanding the neurobiology human trichotillomania, but also other disorders more broadly, especially obsessive compulsive disorder (OCD) (e.g. Greer and Capecchi, 2002; Zuchner et al., 2006; Chen et al., 2010, for review see Camilla et al., 2014). Despite this surge of interest, the neurobiological basis of trichotillomania in humans has received scant research attention to date.

Trichotillomania is a highly familial illness (Keuthen et al., 2014). Genetic and environmental factors and their interactions are likely important in its pathogenesis (Keuthen et al., 2014; Novak et al., 2009; Chattopadhyay 2012), but the precise nature of these factors and their relation with cognitive function and brain structure have not yet 
been identified. There is a search in psychiatry for objective intermediate biological markers, ideally grounded in the neurosciences, which signal 'risk' of developing a given disorder (termed 'endophenotypes') (Gottesman and Gould, 2003). Endophenotypes by definition exist not only in patients with a given disorder but also in their clinically unaffected first-degree relatives, as compared to individuals with no known family history of the condition. While considerable progress has been made in identifying candidate endophenotypes for OCD (Fineberg et al., 2010), no studies have examined biological markers in unaffected relatives of people with trichotillomania.

The brain basis of trichotillomania is unclear; likely there are several key facets of the illness. One model emphasizes three key features: Affect dysregulation, behavioral 'addiction' and cognitive dyscontrol (Stein et al., 2006). Emotion dysregulation can play a role in the maintenance of trichotillomania, in that hair pulling may act to modulate high arousal and low arousal states (Penzel, 2003; Stein et al., 2006; Diefenbach et al., 2008). Hair pulling can also be considered as a candidate behavioral addiction in view of certain parallels with substance addiction (Grant et al., 2007). For example, craving to pull hair can escalate over time and this can be transiently relieved by undertaking the act; treatments of utility in substance dependence show promise for trichotillomania, e.g. opiate antagonists and glutamate modulators (Grant et al., 2009; Grant et al., 2014). Cognitive dyscontrol is suggested by neuropsychological assessments conducted in patients with trichotillomania. Trichotillomania is associated with impaired inhibitory control (Chamberlain et al., 2006; Odlaug et al., 2012), as measured by the Stop-Signal Task (SST), a widely used translational computerized paradigm dependent on the integrity of the right inferior gyrus and other circuitry (Aron et al., 2014). 
Neuroimaging represents a central means of exploring the contribution of neural regions relevant to emotional processing, behavioral addiction, and cognitive control, to the manifestation of trichotillomania. Earlier studies found evidence for structural abnormalities in relevant neural regions, such as reduced grey matter in the putamen and left inferior frontal gyrus and increased grey matter in the right cuneus (Grachev, 2007; O'Sullivan et al., 2007); and reduced cerebellar volumes (Keuthen et al., 2007). The majority of studies to date utilized a region-of-interest (ROI) approach for examining cortical abnormalities: this approach relies on pre-existing knowledge of neurobiology (which is limited for trichotillomania) and can lead to abnormalities in other regions being overlooked (for discussion and review see Chamberlain et al., 2009). Using a whole brain voxel-based morphology (VBM) (rather than ROI) approach, excess grey matter density has been found in patients with trichotillomania compared to controls, in the striatum, amygdalo-hippocampal formation, frontal and cingulate cortices, and supplementary motor cortex (Chamberlain et al., 2008; Chamberlain et al., 2009). In a recent functional neuroimaging study, patients with trichotillomania exhibited dampening of nucleus accumbens responses to reward anticipation (but relative hypersensitivity to gain and loss outcomes) as compared to controls (White et al., 2013). Another fMRI study did not identify abnormal neural activation during implicit sequence learning in patients versus controls (Rauch et al., 2007). In terms of brain structure analysis techniques, the VBM approach is not without its critics: it potentially confounds several parameters, including changes in grey matter thickness, intensity, cortical surface area, and cortical folding (Hutton et al., 2009; Voets et al., 2008; for discussion see Kuhn et al., 2013). Therefore, the alternative approach of 
surface-based morphology has been developed, which is capable of exquisite and sensitive characterization of cortical thickness (Dale et al., 1999; Kuperberg et al., 2003; Reuter et al., 2012).

To address these limitations, we undertook a study of response inhibition and brain structure in individuals affected by trichotillomania and their clinically asymptomatic first-degree relatives. We hypothesized that patients and relatives would show impaired inhibition, coupled with abnormal cortical morphometry in neural regions involved in inhibitory control (especially the right inferior frontal gyrus), along with reduced striatal and cerebellar volumes.

\section{Materials and Methods}

\section{Subjects}

Subjects meeting full DSM-5 criteria for trichotillomania were recruited via media advertisements and psychiatric clinic, on the basis of having at least one firstdegree relative being willing to also participate in the research.

Inclusion criteria for trichotillomania subjects included: 1) Men and women aged 18 to 65 years with a current primary Diagnostic and Statistical Manual of Mental Disorders, Fifth Edition (DSM-5) diagnosis of trichotillomania; 2) no contraindication to MRI; and 3) having one or more first-degree relative willing to participate in the research, also aged 18-65 years, without trichotillomania or other current psychiatric disorder. Exclusion criteria included: 1) unstable medical illness; 2) current pregnancy or inadequate contraception; 3) thoughts of suicide; 4) history of bipolar disorder, dementia, or psychotic disorder; 5) past 12 months substance use disorder; 6) initiation of behavior 
therapy or psychotropic medications within the last 6 months; and 7) current use of illicit drugs based on urine toxicology.

For each subject, one clinically unaffected first-degree relative was also contacted and enrolled, on the basis of not having current trichotillomania or any other DSM-5 disorder (by preference, similarly aged same-gendered sibling were enrolled where possible). Healthy controls were recruited via media advertisements on the basis of no history of psychiatric disorders and no known history of trichotillomania or obsessive compulsive related disorders (for example, OCD, excoriation disorder, body dysmorphic disorder) in first-degree family members.

The study procedures were carried out in accordance with the ethical standards laid out in the latest version of the Declaration of Helsinki. The Institutional Review Board of the University of Chicago approved the study and the consent statement. After complete description of the study to the subjects, written informed consent was obtained.

\section{Procedures}

All subjects first received a psychiatric, medical, and family history evaluation. Clinical instruments included the Mini International Neuropsychiatric Inventory (MINI) (Sheehan et al., 1998), the Massachusetts General Hospital Hairpulling Scale (MGHHPS) (Keuthen et al., 1995), the Clinical Global Impressions Severity Scale (CGI-S) (Guy, 1976), and the Quality of Life Inventory (QoLI) (Frisch and Cornell, 1993).

To provide an objective index of inhibitory control, participants then undertook the computerized Stop-Signal Test (SST) from the Cambridge Neuropsychological Test Automated Battery (CANTAB) (Logan et al., 1984; Aron et al., 2003); this was 
undertaken in a quiet testing environment outside of the scanner. The details of this task are detailed elsewhere (Logan et al., 1984; Aron et al., 2003). In brief, subjects viewed a series of directional arrows appearing on-screen one per time, and made rapid responses depending on the direction of each arrow (left button for left-facing arrow, and vice versa). On a subset of trials, an auditory stop-signal ('beep') occurred following presentation of the directional arrow, signaling to participants that they should attempt to suppress their motor response for the given trial. By varying the time between presentation of the 'go' stimulus and the stop-signal dynamically using a tracking algorithm, the task permitted quantification of stop-signal reaction times (SSRT) - this is an estimate of the time taken by an individual's brain to suppress a response that would normally be undertaken, with longer SSRTs equating to worse impulse control. The task also recorded median response times for 'go' trials and the proportion of successful stops.

After completion of the above, participants undertook high-resolution structural imaging using a 3 Tesla (3T) Philips Achieva Quasar Dual 16 Ch system. Threedimensional MPRAGE scan was obtained with imaging parameters: slab orientation = sagittal, FOV 256x224x176, voxel size 1x1x1 mm3, inversion delay time TI = $900 \mathrm{ms,}$ $\mathrm{TR} / \mathrm{TE}=8.9 / 3.7 \mathrm{~ms}$, flip angle $=8$ degree.

\section{Data Analysis}

Demographic, clinical, and cognitive characteristics between the study groups were compared using one-way analysis of variance (ANOVA, post hoc least significance tests where indicated) or alternative non-parametric tests as described in the text. For the 
purposes of these variables, statistical significance was defined as $\mathrm{p}<0.05$ uncorrected, two-tailed.

MRI scans were processed using FreeSurfer software (version 5.3; http://surfer.nmr.mgh.harvard.edu), using methodology that has previous been described and validated (Kuhn et al., 2013; Dale et al., 1999; Reuter et al., 2012; Makris et al., 2003). In brief, scans for each subject were converted to FreeSurfer format and non-brain tissue was removed using automated algorithms; the resultant images were then transformed to standard Talairach space, segmented, and normalized. After cortical reconstruction, cortical thickness was compared between the study groups, using permutation cluster analysis with stringent correction for multiple comparisons (clusterforming threshold of $\mathrm{p}<0.001$, and cluster-wise $\mathrm{p}$ value $\mathrm{p}<0.05$, two-tailed). We identified regions in which subjects and their relatives together differed significantly from controls in cortical thickness. Mean thickness in each identified cluster for each subject was then extracted and subjected to post hoc tests to further explore group differences (Monte Carlo permutation testing).

Secondary exploratory correlational analyses (Spearman's r) were used to evaluate relationships between: (i) response inhibition and cortical thickness (in all participants and then in each subgroup); (ii) response inhibition and disease severity in the trichotillomania subjects (MGH-HPS and CGI-Severity scores); (iii) cortical thickness and disease severity in the trichotillomania subjects; and (iv) cortical thickness and age (in all participants and then in each subgroup). For the purposes of correlational analyses, significance was defined as $\mathrm{p}<0.05$ uncorrected, two-tailed. 
In addition, volumes of a priori selected subcortical structures of interest (putamen, caudate, accumbens) were extracted, along with cerebellar cortex volumes, using automated parcellation techniques as implemented in FreeSurfer; group differences in volumes of these structures were evaluated using ANOVA ( $p<0.05$, uncorrected, twotailed).

\section{Results}

The mean MGH-HPS symptom score in the patients was 16.7, consistent with moderately severe illness. The 12 randomized patients spent a mean (SD) of 41.0 (35.0) minutes each day pulling hair. Patients pulled from several sites: $10(83.3 \%)$ pulled from their heads, four (33.3\%) from their eyelashes, and two (16.7\%) from their eyebrows. Three of the patients (25\%) had started their pulling before the age of puberty. Of the 12 patients, only four $(33.3 \%)$ had sought outpatient mental health treatment specifically for hair pulling. Two patients (16.7\%) had ongoing psychotherapy (supportive psychotherapy for issues unrelated to trichotillomania) and one (8.3\%) was taking a psychotropic medication (lorazepam for insomnia).

Although individuals with one or more current psychiatric co-morbidity were excluded, eight enrolled patients (66.7\%) reported at least one clinically important lifetime comorbid disorder: 5 (41.7\%) of the 12 subjects reported symptoms consistent with major depressive disorder, and three (25\%) had an anxiety disorder.

Demographic and clinical characteristics of the study groups are summarized in Table 1. It can be seen that there was a significant difference between the groups in terms of age; post hoc tests indicated that this was due to relatives of patients being 
significantly older than patients $(\mathrm{p}=0.004)$ and tending to be older than controls $(\mathrm{p}=0.083)$; patients and controls, however, did not differ from each other in terms of age $(\mathrm{p}=0.150)$. Quality of life scores differed significantly between the groups, with post hoc tests indicating that this was due to significantly poorer quality of life in patients compared to both other groups (both $\mathrm{p}<0.01$ ) while relatives did not differ from controls $(\mathrm{p}=0.366)$.

Stop-Signal Reaction Times (SSRTs) in each group are displayed in Figure 1. Groups differed significantly on SSRTs $(\mathrm{F}=3.493, \mathrm{p}=0.042)$. Post - hoc tests indicated that this was due to patients differing significantly from controls $(\mathrm{p}=0.016)$ and relatives tending to differ from controls ( $\mathrm{p}=0.082$ ), while patients and relatives did not differ from each other $(\mathrm{p}=0.540)$. There was no significant differences between the groups in terms of median 'go' reaction times (mean [SD] TTM: 542.2 [152.3], TTM-Rel: 471.9 [186.5], Controls: 509.8 [169.3]; $\mathrm{F}=1.120, \mathrm{p}=0.300)$ or proportion of successful stops $(0.58$ [0.07], $0.52[0.16] .0 .55[0.12] ; \mathrm{F}=1.840, \mathrm{p}=0.188)$.

\section{* FIGURE 1 AND TABLE 1 ABOUT HERE PLEASE *}

Permutation analysis identified two left-hemisphere clusters and three righthemisphere clusters in which cortical thickness differed significantly between controls and the proband-relative pairs (Table 2). As can be seen in Figure 2, trichotillomania patients showed significantly greater cortical thickness in these clusters compared to controls, as did their relatives. Patients did not differ significantly from their relatives on cortical thickness in these clusters, with the exception of the cluster comprising right lateral occipital cortex, in which relatives showed significantly greater cortical thickness 
than patients. Cortical thickness in these clusters did not correlate significantly with response inhibition or age (considered for all subjects together and each group separately), nor with disease severity in patients (all $\mathrm{p}>0.08$ ).

\section{* TABLE 2 AND FIGURE 2 ABOUT HERE PLEASE *}

The average volumes of selected subcortical regions of interest, and the cerebellar cortices, in each study group are indicated in Table 3. It can be seen that no effect of group approached significance for striatum volumes (all $p>0.10$ ). There was a nonsignificant trend for an effect of group on right but not left cerebellar cortex volumes, due to numerically lower volumes in relatives and, to a lesser degree, patients versus controls.

\section{* TABLE 3 ABOUT HERE PLEASE *}

\section{Discussion}

To the knowledge of the authors, this is the first study to evaluate potential biological vulnerability markers for trichotillomania. The key findings were: (i) that groups differed on response inhibition, due to impaired performance in patients, and intermediate performance in relatives, versus controls; and (ii) that patients with trichotillomania and their unaffected first-degree relatives showed an excess of cortical thickness, compared to controls, in several discrete regions: the right middle and inferior frontal gyri (BA $11 \& 47$ ), right lingual gyrus (BA 18), left superior temporal cortex (BA 21), and left precuneus (BA 7). These results have important implications for understanding the neurobiological basis of trichotillomania and its relationship with other conditions. 
As discussed earlier, the neurobiological basis of trichotillomania is not well characterized (Chamberlain et al., 2009). The handful of imaging studies so far provide partial support for trichotillomania being associated with smaller left putamen volumes (O'Sullivan et al., 1997), reduced cerebellar volumes (Keuthen et al., 2007), and excess grey matter densities in left striatum, left amygdalo-hippocampal formation, and multiple cortical regions bilaterally (Chamberlain et al., 2008). Thus, the disorder can be conceptualized in terms of abnormalities of cortico-subcortical circuitry involved in affect regulation, habit generation and top-down control (Stein et al., 2006). Also relevant is the likely role of reward circuitry in trichotillomania, as a recent fMRI study found abnormal accumbens activation in patients during a reward task, along with decreased accumbens connectivity to other neural regions during the resting state (White et al., 2013). In this study, we found common abnormalities of cortical thickness in neural regions germane to inhibitory control, emotional processing, and awareness, in patients with trichotillomania and their symptomatically unaffected first-degree relatives. Consistent with our prediction, excess cortical thickness was found in the right medial/inferior frontal gyri (BA $11 \& 47$ ), key neural nodes involved in top-down control (Aron et al., 2014;Bari and Robbins, 2013; Cromheek and Mueller, 2014). The repetitive hair pulling habit characteristic of trichotillomania is strongly suggestive of difficulties with top-down response suppression, while deficits on the Stop Signal Task (SST), an objective measure of inhibitory control, have been found in patients (Chamberlain et al., 2006; Odlaug et al., 2012). Also consistent with our hypotheses, we found that the study groups differed significantly in terms of response inhibition (SST), due to patients being significantly impaired, and relatives occupying an intermediate position, versus controls. 
As anticipated, groups did not differ significantly on the median reaction time for 'go' trials on the task, nor for proportion of correct responses.

Contrary to our prediction, patients did not differ significantly from controls in terms of dorsal and ventral striatum volumes. This finding is somewhat discordant with the previous report of reduced grey matter in the putamen in trichotillomania (O'Sullivan et al., 1997) and with existing neurobiological models implicating the striatum in the pathophysiology of the disorder (given its role in reward processing, and habit generation). Nonetheless, in contrast to our cortex analysis, the subcortical analysis by necessity relied on a region of interest (ROI) approach rather than permutation cluster analysis, which may have limited power to detect effects of group. It remains possible that the striatum plays a role in trichotillomania but that this is not reflected at a structural (as opposed to functional) level. With respect to cerebellar volumes, while groups did not differ significantly for cerebellar volumes herein, there was a right-lateralized trend towards an effect of group ( $\mathrm{p}=0.054$ uncorrected); numerically, cerebellar volumes were lower in patient relatives, and, to a lesser degree, patients versus controls. Previous work found some evidence for reduced cerebellar volumes in trichotillomania, using a more fine-grained method of parcellating particular cortical regions than was utilized here (Keuthen et al., 2007).

The finding of morphometric abnormalities in trichotillomania patients and their relatives in the precuneus (BA 7), temporal lobe (BA 21), and lingual gyrus (BA 18), was not predicted a priori. In a recent functional magnetic resonance imaging (fMRI) metaanalysis, the precuneus (BA 7) emerged as a region involved in the integration of emotion and top-down cognitive control (Cromheeke and Mueller, 2014). The superior 
temporal lobe (BA 21) and precuneus form part of neural circuitry involved in memory processing (Tulving et al., 1999), there also being some evidence that BA 21 plays a role in self-awareness/monitoring according to data from Alzheimer's Disease (Amanzio et al., 2011). Some studies have found mnemonic impairments in trichotillomania (Chamberlain et al., 2009). It is intriguing to note that emotion regulation plays a role in hair pulling (Shusterman et al., 2009; Rufer et al., 2014). Furthermore, awareness training and self-monitoring are core principles of Habit Reversal Therapy (HRT), one of the few established effective treatments for the condition (Azrin et al., 1980; Bloch et al., 2007; Morris et al., 2013). Further research will be needed to characterize the functional implications of abnormal cortical thickness in these regions in people at risk of trichotillomania.

It is potentially informative to compare the cortical thickness findings in trichotillomania to those previously reported for OCD, given the suggested relationship between these two conditions, in that trichotillomania is currently conceptualized as an OC Related Disorder in the DSM-5. Cortical thickness findings in OCD patients are conflicting, with some studies finding increased (Narayan et al., 2008; Fan et al., 2013) and other reduced (Kuhn et al., 2013; Venkatasubramanian et al., 2012; Fullana et al., 2014; Nakamae et al., 2012; Shin et al., 2007) cortical thickness compared to controls. To the knowledge of the authors, there have been two studies that have quantified cortical thickness in unaffected relatives of OCD patients. Shaw and colleagues reported excess cortical thickness in unaffected relatives of patients with OCD versus controls in the right lateral prefrontal cortex, left medial temporal lobe, and right precuneus (Shaw et al., 2014). Peng and coworkers found reduced cortical thickness in OCD patients and their 
relatives compared to controls, in left parietal and right superior temporal regions (Peng et al., 2014). These findings differ considerably from the current findings in people with trichotillomania and their relatives, suggesting that the disorders are distinct and likely mediated by different vulnerability markers. The findings here for trichotillomania also differ from findings in attention-deficit hyperactivity disorder (ADHD), in which reduced thickness of the right superior frontal gyrus was found (Almeida et al., 2010; Batty et al., 2010).

While this study is the first of its kind in trichotillomania, several caveats should be noted. The sample size was relatively small, which may have limited statistical power. While this is unlikely to have been problematic for the primary analysis (since we used permutation cluster analysis, which permits powerful identification of thickness abnormalities yet stringent correction for multiple comparisons), the secondary correlational analyses in particular may have been prone to type II error (false negatives). The study was neither designed nor powered to investigate effects of medication, therapy, or comorbidities on cortical and SST findings in trichotillomania; however, given that similar results were found in non-medicated first-degree relatives without symptoms, we can refute the possibility that the findings in relatives were substantially mediated by these potential confounds. Only two patients were receiving psychotherapy (supportive psychotherapy for issues unrelated to trichotillomania) and only one was taking psychotropic medication (lorazepam for insomnia) and so we feel that it was unlikely that the findings were mediated substantively by these factors. In summary, impaired response inhibition and excess cortical thickness in the right middle/inferior frontal gyri, and other focal regions, were found in people with trichotillomania and their symptom- 
free first-degree relatives. These biological markers represent candidate endophenotypes for this disorder, and appear to overlap only to a limited extent with those already identified for OCD. It is conceivable that cortical thickening in neural regions could reflect a compensatory response to other areas of impairment, although we did not find any regions of reduced cortical thickness in patients. It will be important for future work to expand on these results using larger sample sizes, ideally incorporating not only structural but also functional brain measures, and to consider their relationship with genetic polymorphisms. 


\section{Conflict of Interest}

Dr. Chamberlain consults for Cambridge Cognition. Mr. Odlaug received a research grant from the Trichotillomania Learning Center, consults for H. Lundbeck Pharmaceuticals, and has received royalties from Oxford University Press. Mr. Leppink and Ms. Derbyshire report no financial or other conflicts of interest. Dr. Grant has received research grants from NIMH, National Center for Responsible Gaming, Forest, and Roche Pharmaceuticals. Dr. Grant receives yearly compensation from Springer Publishing for acting as Editor-in-Chief of the Journal of Gambling Studies and has received royalties from Oxford University Press, American Psychiatric Publishing, Inc., Norton Press, and McGraw Hill.

\section{Acknowledgements}

This research was supported by a grant from the Trichotillomania Learning Center, USA, to Mr. Odlaug and by a grant from the Academy of Medical Sciences, UK, to Dr.

Chamberlain. 
Table 1. Demographic, Clinical, and Cognitive Findings across the three study groups

\begin{tabular}{|c|c|c|c|c|c|}
\hline & TTM & $\begin{array}{c}\text { First- } \\
\text { Degree } \\
\text { Relatives of } \\
\text { TTM } \\
\end{array}$ & $\begin{array}{l}\text { Healthy } \\
\text { Controls }\end{array}$ & $\begin{array}{c}\text { ANOVA } \\
\text { F } \\
\text { statistic }\end{array}$ & $\begin{array}{c}\text { p- } \\
\text { value }\end{array}$ \\
\hline & $(\mathrm{N}=12)$ & $(\mathrm{N}=10)$ & $(\mathrm{N}=14)$ & & \\
\hline Age, years & $25.8(4.5)$ & $41.8(15.1)$ & $32.9(14.0)$ & 4.749 & 0.015 \\
\hline Sex, female, n (\%) & $11(91.7 \%)$ & $8(80 \%)$ & $14(100 \%)$ & & \\
\hline Education Score) & $3.8(1.0)$ & $4.0(0.7)$ & $3.9(0.9)$ & 0.105 & 0.9 \\
\hline Quality of Life Score & $24.3(18.1)$ & $54.4(18.0)$ & $48.0(14.9)$ & 10.173 & $<0.001$ \\
\hline MGH-HPS, total score & $16.7(4.6)$ & N/A & N/A & & \\
\hline CGI Severity & $4.5(0.67)$ & N/A & N/A & & \\
\hline
\end{tabular}

Values are mean (SD) unless otherwise indicated.

Abbreviations: MGH-HPS: Massachusetts General Hospital Hairpulling Scale; SSRT = Stop-Signal

Reaction Time; SST = Stop-Signal Test. 
Table 2. Results of Permutation Cluster Analysis. Clusters showing significant differences in cortical thickness between at risk individuals (patients and relatives) versus controls

\begin{tabular}{|r|r|l|l|l|l|l|l|}
\hline & & \multicolumn{7}{|c|}{$\begin{array}{c}\text { Cluster peak co-ordinates } \\
\text { (Talairach) }\end{array}$} & \\
\hline Cluster & Max & $\begin{array}{l}\text { Area } \\
\left(\mathrm{mm}^{2}\right)\end{array}$ & $\mathrm{X}$ & $\mathrm{Y}$ & $\mathrm{Z}$ & $\begin{array}{l}\text { Cluster p } \\
\text { value }\end{array}$ & $\begin{array}{l}\text { Cortical Region } \\
\text { (Brodmann Area) }\end{array}$ \\
\hline \multicolumn{2}{|l|}{ Left Hemisphere } \\
\hline
\end{tabular}


Table 3. Volumes of subcortical structures and cerebellar cortex across study groups (cubic $\mathrm{mm}$ )

\begin{tabular}{|c|c|c|c|c|c|}
\hline & TTM & $\begin{array}{c}\text { First- } \\
\text { Degree } \\
\text { Relatives of } \\
\text { TTM }\end{array}$ & $\begin{array}{l}\text { Healthy } \\
\text { Controls }\end{array}$ & $\begin{array}{c}\text { ANOVA } \\
\text { F } \\
\text { statistic }\end{array}$ & $\begin{array}{c}\text { p- } \\
\text { value }\end{array}$ \\
\hline & $(\mathrm{N}=12)$ & $(\mathrm{N}=10)$ & $(\mathrm{N}=14)$ & & \\
\hline Left caudate & $\begin{array}{l}3810.3 \\
(306.4)\end{array}$ & $\begin{array}{l}3603.4 \\
(334.2)\end{array}$ & $\begin{array}{l}3695.1 \\
(467.9)\end{array}$ & 0.801 & 0.457 \\
\hline Left putamen & $\begin{array}{l}6767.4 \\
(800.8)\end{array}$ & $\begin{array}{l}6443.1 \\
(511.5)\end{array}$ & $\begin{array}{l}6153.0 \\
(768.6)\end{array}$ & 2.235 & 0.123 \\
\hline Left nucleus accumbens & $\begin{array}{c}751.5 \\
(115.3)\end{array}$ & $\begin{array}{c}763.8 \\
(118.1)\end{array}$ & $\begin{array}{c}820.4 \\
(135.9)\end{array}$ & 1.134 & 0.334 \\
\hline Left cerebellar cortex & $\begin{array}{l}48844.3 \\
(3205.3)\end{array}$ & $\begin{array}{l}47234.4 \\
(3211.2)\end{array}$ & $\begin{array}{l}49279.6 \\
(5697.0)\end{array}$ & 0.678 & 0.515 \\
\hline Right caudate & $\begin{array}{l}3981.9 \\
(275.3)\end{array}$ & $\begin{array}{l}3734.3 \\
(370.2)\end{array}$ & $\begin{array}{l}3909.1 \\
(501.0)\end{array}$ & 1.076 & 0.352 \\
\hline Right putamen & $\begin{array}{l}6136.2 \\
(451.9)\end{array}$ & $\begin{array}{l}5981.9 \\
(757.9)\end{array}$ & $\begin{array}{l}6361.5 \\
(638.6)\end{array}$ & 1.137 & 0.333 \\
\hline Right nucleus accumbens & $731.9(88.8)$ & $663.8(91.4)$ & $\begin{array}{c}724.8 \\
(139.5)\end{array}$ & 1.527 & 0.232 \\
\hline Right cerebellar cortex & $\begin{array}{l}48283.2 \\
(3342.6)\end{array}$ & $\begin{array}{l}46842.9 \\
(3768.9)\end{array}$ & $\begin{array}{l}51199.8 \\
(5356.9)\end{array}$ & 3.186 & 0.054 \\
\hline
\end{tabular}

Values are mean (SD) unless otherwise indicated. 
Figure 1. Inhibitory control performance on the Stop-Signal Test (Stop-Signal Reaction Times). Groups differed overall, due to significant impairment in patients versus controls, and a trend towards impairment in relatives versus controls. ${ }^{*}=\mathrm{p}<0.05$, LSD test; $\mathrm{t}=0.05<\mathrm{p}<0.10 ;$ n. $\mathrm{s} .=\mathrm{p}>0.10$. 
Figure 2. Renderings showing significant clusters of abnormal cortical thickness in trichotillomania patients and their relatives compared to controls (red, significant at cluster-forming threshold $\mathrm{p}<0.001$, cluster-threshold $\mathrm{p}<0.05)$. Graphs indicate extracted mean (SEM) thickness in each cluster for each group and post hoc comparisons. ** $\mathrm{p}<0.01$, *** $\mathrm{p}<0.001$, by Monte Carlo permutation tests. $\mathrm{L}=$ left-hemisphere, $\mathrm{R}=$ righthemisphere. 


\section{References}

Almeida LG, Ricardo-Garcell J, Prado H, et al. (2010). Reduced right frontal cortical thickness in children, adolescents and adults with ADHD and its correlation to clinical variables: a cross-sectional study. J Psychiatr Res. 44(16):1214-1223.

Amanzio M, Torta DM, Sacco K, et al. (2011). Unawareness of deficits in Alzheimer's disease: role of the cingulate cortex. Brain. 134(Pt 4):1061-1076.

Azrin NH, Nunn RG, Frantz SE. (1980). Treatment of hairpulling (trichotillomania): a comparative study of habit reversal and negative practice training. J Behav Ther \& Exp Psychiat. 11:13-20.

Aron AR, Fletcher PC, Bullmore ET, Sahakian BJ, Robbins TW. (2003). Stop-signal inhibition disrupted by damage to right inferior frontal gyrus in humans. Nat Neurosci. 6(2):115-116.

Aron AR, Robbins TW, Poldrack RA. (2014). Inhibition and the right inferior frontal cortex: one decade on. Trends Cogn Sci. 18(4):177-185.

Bari A, Robbins TW. (2013). Inhibition and impulsivity: behavioral and neural basis of response control. Prog Neurobio. 108:44-79.

Batty MJ, Liddle EB, Pitiot A, et al. (2010). Cortical gray matter in attentiondeficit/hyperactivity disorder: a structural magnetic resonance imaging study. J Am Acad Child Adolesc Psychiatry. 49(3):229-238.

Bloch MH, Landeros-Weisenberger A, Dombrowski P, et al. (2007). Systematic review: Pharmacological and behavioral treatment for trichotillomania. Biol Psychiatry. 62(8):839-846.

Camilla d'Angelo LS, Eagle DM, Grant JE, et al. (2014). Animal models of obsessivecompulsive spectrum disorders. CNS Spectrums. 19(1):28-49.

Chamberlain SR, Fineberg NA, Blackwell AD, et al. (2006). Motor inhibition and cognitive flexibility in obsessive-compulsive disorder and trichotillomania. Am J Psychiatry. 163(7):1282-1284.

Chamberlain SR, Menzies LA, Fineberg NA, et al. (2008). Grey matter abnormalities in trichotillomania: morphometric magnetic resonance imaging study. Brit J Psychiatry. 193(3):216-121.

Chamberlain SR, Odlaug BL, Boulougouris V, et al. (2009). Trichotillomania: neurobiology and treatment. Neurosci Biobehav Rev. 33(6):831-842. 
Chattopadhyay K. (2012). The genetic factors influencing the development of trichotillomania. J Genet. 91(2):259-262.

Chen SK, Tvrdik P, Peden E, et al. (2010). Hematopoietic origin of pathological grooming in Hoxb8 mutant mice. Cell. 141(5):775-785.

Christenson GA, Pyle RL, Mitchell JE. (1991). Estimated lifetime prevalence of trichotillomania in college students. J Clin Psychiatry. 52(10):415-417.

Cromheeke S, Mueller SC. (2014). Probing emotional influences on cognitive control: an ALE meta-analysis of cognition emotion interactions. Brain Struc Func. 219(3):9951008 .

Dale AM, Fischl B, Sereno MI. (1999). Cortical surface-based analysis. I. Segmentation and surface reconstruction. NeuroImage. 9(2):179-194.

Diefenbach GJ, Tolin DF, Meunier S, Worhunsky P. (2008). Emotion regulation and trichotillomania: a comparison of clinical and nonclinical hair pulling. J Behav Ther Exp Psychiatry. 39(1):32-41.

Fan Q, Palaniyappan L, Tan L, et al. (2013). Surface anatomical profile of the cerebral cortex in obsessive-compulsive disorder: a study of cortical thickness, folding and surface area. Psychol Med. 43(5):1081-1091.

Fineberg NA, Chamberlain SR, Hollander E, et al. (2011). Translational approaches to obsessive-compulsive disorder: from animal models to clinical treatment. $\mathrm{Br} \mathrm{J}$ Pharmacol. 164(4):1044-1061.

Fineberg NA, Potenza MN, Chamberlain SR, et al. (2010). Probing compulsive and impulsive behaviors, from animal models to endophenotypes: a narrative review. Neuropsychopharmacol. 35(3):591-604.

Frisch MB, Cornell J MV. (1993). Clinical validation of the Quality of Life Inventory: a measure of life satisfaction for use in treatment planning and outcome assessment. Psychol Assess. 4(1):92-101.

Fullana MA, Cardoner N, Alonso P, et al. (2014). Brain regions related to fear extinction in obsessive-compulsive disorder and its relation to exposure therapy outcome: a morphometric study. Psychol Med. 44(4):845-856.

Gottesman, II, Gould TD. (2003). The endophenotype concept in psychiatry: etymology and strategic intentions. Am J Psychiatry. 160(4):636-645.

Grachev ID. (1997). MRI-based morphometric topographic parcellation of human neocortex in trichotillomania. Psychiatry Clin Neurosci. 51(5):315-321. 
Grant JE, Odlaug BL, Potenza MN. (2007). Addicted to hair pulling? How an alternate model of trichotillomania may improve treatment outcome. Harv Rev Psychiatry. 15(2):80-85.

Grant JE, Odlaug BL, Kim SW. (2009). N-acetylcysteine, a glutamate modulator, in the treatment of trichotillomania: a double-blind, placebo-controlled study. Arch Gen Psychiatry. 66(7):756-763.

Grant JE, Odlaug BL, Schreiber LR, Kim SW. (2014). The opiate antagonist, naltrexone, in the treatment of trichotillomania: results of a double-blind, placebo-controlled study. $\mathrm{J}$ Clin Psychopharmacol. 34(1):134-138.

Greer JM, Capecchi MR. (2002). Hoxb8 is required for normal grooming behavior in mice. Neuron. 33(1):23-34.

Guy W. (1976). Clinical Global Impressions. ECDEU Assessment Manual for Psychopharmacology. pp. 218-22.

Hallopeau M. (1889). Alopicie par grattage (trichomanie ou trichotillomanie). Ann Dermatol Venereol 10:440-441.

Hutton C, Draganski B, Ashburner J, et al. (2009). A comparison between voxel-based cortical thickness and voxel-based morphometry in normal aging. NeuroImage. 48(2):371-380.

Keuthen NJ, Altenburger EM, Pauls D. (2014). A family study of trichotillomania and chronic hair pulling. Am J Med Genet B Neuropsychiatr Genet. 165B(2):167-174.

Keuthen NJ, Makris N, Schlerf JE, Martis B, Savage CR, McMullin K, et al. (2007). Evidence for reduced cerebellar volumes in trichotillomania. Biol Psychiatry. 61(3):374381.

Keuthen NJ, O'Sullivan RL, Ricciardi JN, et al. (1995). The Massachusetts General Hospital (MGH) Hairpulling Scale: 1. development and factor analyses. Psychother Psychosom. 64(3-4):141-145.

Kuhn S, Kaufmann C, Simon D, et al. (2013). Reduced thickness of anterior cingulate cortex in obsessive-compulsive disorder. Cortex. 49(8):2178-2185.

Kuperberg GR, Broome MR, McGuire PK, et al. (2003). Regionally localized thinning of the cerebral cortex in schizophrenia. Arch Gen Psychiatry. 60(9):878-888.

Logan GD, Cowan WB, Davis KA. (1984). On the ability to inhibit simple and choice reaction time responses: a model and a method. J Exp Psychol Hum Percept Perform. 10(2):276-291. 
Makris N, Hodge SM, Haselgrove C, Kennedy DN, Dale A, Fischl B, et al. (2003). Human cerebellum: surface-assisted cortical parcellation and volumetry with magnetic resonance imaging. J Cog Neurosci. 15(4):584-599.

Morris SH, Zickgraf HF, Dingfelder HE, et al. (2013). Habit reversal training in trichotillomania: guide for the clinician. Expert Rev Neurother. 13(9):1069-1077.

Nakamae T, Narumoto J, Sakai Y, et al. (2012). Reduced cortical thickness in nonmedicated patients with obsessive-compulsive disorder. Prog Neuropsychopharmacol Biol Psychiatry. 37(1):90-95.

Narayan VM, Narr KL, Phillips OR, et al. (2008). Greater regional cortical gray matter thickness in obsessive-compulsive disorder. Neuroreport. 19(15):1551-1555.

Novak CE, Keuthen NJ, Stewart SE, et al. (2009). A twin concordance study of trichotillomania. Am J Med Genet B Neuropsychiatr Genet. 150B(7):944-949.

Odlaug BL, Chamberlain SR, Harvanko AM, et al. (2012). Age at onset in trichotillomania:clinical variables and neurocognitive performance. Prim Care Companion CNS Disord. 14(4).

Odlaug BL, Grant JE. (2010). Impulse-control disorders in a college sample: results from the self-administered Minnesota Impulse Disorders Interview (MIDI). Prim Care Companion J Clin Psychiatry. 12(2).

Odlaug BL, Kim SW, Grant JE. (2010). Quality of life and clinical severity in pathological skin picking and trichotillomania. J Anxiety Dis. 24(8):823-829.

O'Sullivan RL, Rauch SL, Breiter HC, Grachev ID, Baer L, Kennedy DN, et al. (1997). Reduced basal ganglia volumes in trichotillomania measured via morphometric magnetic resonance imaging. Biol Psychiatry. 42(1):39-45.

Peng Z, Shi F, Shi C, et al. (2014). Structural and diffusion property alterations in unaffected siblings of patients with obsessive-compulsive disorder. PLoS One. 9(1):e85663.

Penzel F. (2003). The hair-pulling problem: A complete guide to trichotillomania. New York: Oxford University Press.

Rauch SL, Wright CI, Savage CR, et al. (2007). Brain activation during implicit sequence learning in individuals with trichotillomania. Psychiatry Res. 154(3):233-240.

Reuter M, Schmansky NJ, Rosas HD, et al. (2012). Within-subject template estimation for unbiased longitudinal image analysis. NeuroImage. 61(4):1402-1418. 
Rufer M, Bamert T, Klaghofer R, et al. (2014). Trichotillomania and emotion regulation: Is symptom severity related to alexithymia? Psychiatry Res. 218(1-2):161-165.

Shaw P, Sharp W, Sudre G, et al. (2014). Subcortical and cortical morphological anomalies as an endophenotype in obsessive-compulsive disorder. Mol Psychiatry. Epub 2014/02/12.

Sheehan DV, Lecrubier Y, Sheehan KH, et al. (1998). The Mini-International Neuropsychiatric Interview (M.I.N.I.): the development and validation of a structured diagnostic psychiatric interview for DSM-IV and ICD-10. J Clin Psychiatry. 59 Suppl 20:22-33.

Shin YW, Yoo SY, Lee JK, et al. (2007). Cortical thinning in obsessive compulsive disorder. Hum Brain Mapp. 28(11):1128-1135.

Shusterman A, Feld L, Baer L, et al. (2009). Affective regulation in trichotillomania: Evidence from a large-scale internet survey. Behav Res Ther. 47(8):637-644.

Stein DJ, Chamberlain SR, Fineberg N. (2006). An A-B-C model of habit disorders: hairpulling, skin-picking, and other stereotypic conditions. CNS Spectrums. 11(11):824-827.

Tulving E, Habib R, Nyberg L, et al. (1999). Positron emission tomography correlations in and beyond medial temporal lobes. Hippocampus. 19(1):71-82.

Venkatasubramanian G, Zutshi A, Jindal S, et al. (2012). Comprehensive evaluation of cortical structure abnormalities in drug-naive, adult patients with obsessive-compulsive disorder: a surface-based morphometry study. J Pysch Res. 46(9):1161-1168.

Voets NL, Hough MG, Douaud G, et al. (2008). Evidence for abnormalities of cortical development in adolescent-onset schizophrenia. NeuroImage. 43(4):665-675.

White MP, Shirer WR, Molfino MJ, Tenison C, Damoiseaux JS, Greicius MD. (2013). Disordered reward processing and functional connectivity in trichotillomania: a pilot study. J Psychiatr Res. 47(9):1264-1272.

Woods DW, Flessner CA, Franklin ME, et al. (2006). The Trichotillomania Impact Project (TIP): exploring phenomenology, functional impairment, and treatment utilization. J Clin Psychiatry. 67(12):1877-1888.

Zuchner S, Cuccaro ML, Tran-Viet KN, et al. (2006). SLITRK1 mutations in trichotillomania. Mol Psychiatry. 11(10):887-889. 